\title{
Role of Endoscopy in Laparoscopic Procedures
}

\author{
Mohamed O. Othman, Mihir Patel and Timothy Woodward \\ Mayo Clinic Jacksonville \\ USA
}

\section{Introduction}

Endoscopy is a viable tool in the diagnosis and management of various gastrointestinal disorders. In this chapter we will discuss the role of Endoscopy in facilitating laparoscopic procedures. Endoscopy can be done before, during or after the laparoscopic procedures and can be an alternative management technique for laparoscopy. We will focus on the recent advances in the frontier and what the future holds.

\section{Endoscopy prior to laparoscopy}

\subsection{Tattooing prior to laparoscopic resection}

Accurate localization of the surgical site is crucial prior to laparoscopic resection. Flat colorectal polyps or cancer are often hard to localize by visualization of the colonic wall or even by palpation. Measuring the distance of the lesion from the anal verge or correlating with a barium enema is usually not accurate enough for localizing the segment prior to colonic resection. Intra-operative colonoscopy is accurate in localizing the lesions, but it might interfere with patient positioning or laparoscopic field by air insufflation; in addition to prolonging the procedure time looking for the lesion.

Endoscopic tattooing of the lesion prior to laparoscopic resection has proven to be accurate and efficient. Feingold et al in a retrospective study of 50 patients who underwent endoscopic tattooing prior to laparoscopic resection found that $88 \%$ of these lesions were accurately localized during the laparoscopic procedure; no complications were reported.[1] Many agents have been studied for use in endoscopic tattooing. Methylene blue and indigo carmine can successfully stain the serosa. However, these agents disappear in few days, making it not suitable for endoscopic tattooing. [2,3] Indian ink, however, can stain the serosa for years making it the ideal agent for tattooing [4]. Indian ink should be sterilized and diluted prior to injection [5]. A prepackaged sterilized and already diluted Indian ink, SPOT® (GI Supply, Camp Hill, Pennsylvania, USA) is currently used by many endoscopists for endoscopic tattooing [6]. It is recommended to inject the tattoo in 3 circumferential sites distal to lesion in case one of these sites is on the mesenteric side of the colon [4] The longterm safety of Indian ink was evaluated in a study of 55 patients; no clinical complications such as fever, infection or abdominal pain were reported. There was mild chronic inflammation at the site of injection in 6 patients without clinical significance[7]. Intraperitoneal spillage of Indian ink can happen and it is usually without clinical 
significance. There are a few case reports of peritonitis or peritoneal abscess as a result of intraperitoneal spillage [8].

Preoperative endoscopic tattooing of pancreatic lesions prior to laparoscopic distal pancreatectomy has been recently reported [9]. This technique utilizes endoscopic ultrasound with the use of a fine needle for tattooing under endoscopic guidance. In a study of 36 patients who underwent laparoscopic distal pancreatictomy, 10 patients had preoperative endoscopic tattooing. Patients in the preoperative tattooing group had shorter operation times compared to the control group [10]. Figure 1 Illustrate tattooing of duodenal lesion prior to laparoscopic removal.

\subsection{Endoscopic sphincterotomy prior to laparoscopic cholecystectomy}

Common bile duct stones are found in $10 \%$ of patients undergoing elective cholecystectomy [11]. In these patients, management of common bile duct stones includes endoscopic sphincterotomy (ES) prior to or after laparoscopic cholecystectomy (LC) or LC with intraoperative common bile duct exploration. Many studies evaluated both approaches with controversial outcomes. A meta-analysis of 12 studies did not find any difference in mortality, morbidity or in the need for an additional procedure between both approaches [12]. However, a decision analysis published in 2008 suggested that LC with intraoperative bile duct exploration is superior to ES with LC [13]. Most likely, these controversial results could be explained by the difference in expertise among surgeons in performing laparoscopic common bile duct exploration. Recently, Intraoperative Endoscopic sphicnterotomy by Endoscopic Retrograde Cholangiopancreatography (ERCP) during LC was introduced as an alternative technique for the management of Choledocholithiasis. Enochsson et al. evaluated this technique in 37 patients with a $93.5 \%$ success rate and none of the patients developed post ERCP pancreatitis [14]. Intraoperative ERCP was compared to preoperative ERCP in patients with choledocholithiasis in a study by ElGeidie et al. The study included 198 patients and it did not find any difference in the morbidity or in the procedure time between the two approaches [15]. However, Intraoperative ERCP during LC has the advantage of being able to perform the procedure and surgery in a single stage procedure, making it an attractive option.

\section{Endoscopy during laparoscopy (combined laparoscopic endoscopic procedure)}

\subsection{Laparoscopic monitored colonoscopic polypectomy (LMCP) to avoid segmental colon resection}

The majority of large colonic polyps can be resected with colonoscopy. In few circumstances, patients are referred to laparascopic segmental colonic resection either because of the polyp size or because of the polyp location. Laparoscopic monitored colonoscopic polypectomy was suggested as a new technique which can reduce the number of segmental colonic resections. In this technique, the laparoscope can guide the endoscope to the site of the polyp and mobilize the colon to achieve easier polypectomy. This technique is particularly valuable in patients with angulated sigmoid colon from prior surgery and adhesion. This technique was evaluated in a study by Grunhagen et al in which 11 patients with difficult polypectomy were enrolled. Segmental colonic resection was avoided in 9 patients. No residual polyps were seen in the follow-up period [16]. Another trial included 47 patients who had LMCP and showed that $97 \%$ of the patients had a successful procedure 
without any complications[17]. In another trial from Germany that included 23 patients, LMCP was successful in 17 patients [18]. In all previously mentioned trials, there was minimal to no discomfort from the laparoscopic part of the procedure.

\subsection{Endoscopy assisted laparoscopic wedge resection}

Laparoscopic wedge resection is currently the standard of care for the removal of gastric submucosal tumor and in particular Gastrointestinal Stromal Tumor (GIST). Laparoscopic wedge resection is more feasible in tumors located at the anterior wall of the stomach Tumors located in the posterior wall of the stomach or the gastro-esophageal junctions were traditionally managed by surgery to ensure negative margins and to avoid excessive gastric resection. Endoscopy assisted laparoscopic wedge resection was successfully performed in gastric submucosal tumors located in the above mentioned area to spare open surgery. In this technique, endoscopy is used simultaneously during laparoscopy to localize the tumor and ensure negative margins. In a trial of 18 patients, this technique was proven successful with a single complication (perforation) in one case [19]. A new technique described by Hiki et al utilizes endoscopic submucosal dissection (ESD) of three-fourths of the circumference around the submucosal tumor followed by seromuscular dissection of the exact threefourths of the circumference by laparoscopy then the tumor is removed by a laparoscopic stapling device [20]. This technique is successful regardless of the tumor location and the initial ESD done by endoscopy to ensure the exact margins of the tumor.

\subsection{Combined colonoscopy and laparoscopy to close colonic perforation}

Iatrogenic colonic perforation can be treated with segmental laparoscopic resection or with laparoscopic suturing [21]. A new technique was proposed to close iatrogenic colonic perforation with combined endoscopy and laparoscopy approach. This technique involves mucosal closure using endoscopic clips, serosal closure using laparoscopy and a leak test with air insufflations and water irrigation [22].

\subsection{Combined laparoscopic-endoscopic approach for duodenal lesions}

Endoscopic mucosal resection and endoscopic mucosal dissection of duodenal lesions is feasible [23]. However, it is complicated with higher rates of bleeding, perforation and tumor recurrence compared to EMR and ESD of colonic and stomach lesions [24]. Sakon et al described a new technique utilizing ESD of the margins of the duodenal lesion followed by laparoscopic resection. This promising technique was associated with less procedure time and minimal bleeding [25].

\subsection{Laparoscopy assisted foreign body removal}

Most of ingested foreign body can be removed endoscopically. In few instances, sharp foreign body can invade through the gastrointestinal wall to other organ and require surgical assistance. Lanitis et al described a case in which a patient ingested two sharp needles, one of them migrated to the liver and another one invaded into the abdominal wall. Combined endoscopy and laparoscopy technique was successful in removing both lesions [26]. Another case report described the removal of large dental bridge by the combined approach. The foreign body was snared by the endoscopy in the stomach but it could not pass through the overtube in the esophagus. Gastrostomy was done using laparoscope then the snared foreign body was delivered to a laparoscopy grasper through the gastrostomy 
[27]. This technique has many advantages in difficult cases of foreign body removal. Endoscopy provides trans-illumination of the stomach and help to localize the foreign body for laparoscopic removal. In addition, laparoscopy provides the opportunity to clean the peritoneal spillage and ensure the closure of the abdominal wall [28].

\section{Endoscopy after laparoscopy}

\subsection{Endoscopy in the treatment of bariatric surgery complications}

Morbid obesity and its complications became an endemic problem in most developed countries [29]. Laparoscopic bariatric surgery has gained popularity in the field of surgical treatment of obesity. Laparoscopic gastric bypass and laparoscopic adjustable gastric banding account for more than $50 \%$ of bariatric surgeries performed worldwide [30]. Endoscopy is a useful tool in assessing complications of bariatric surgeries in addition to its role in the initial assessment of these patients prior to surgery.

Stomal stenosis is the one of the most frequent complications after Laparoscopic Roux en $Y$ Gastric Bypass ( RYGBP) [31]. Stomal stenosis occurs in $1-5 \%$ of patients undergoing Laparoscopic RYGBP [32-34]. Endoscopic dilation of the stomal stenosis has proven to be successful without the need of surgical revision. Ukleja et al performed endoscopic balloon dilation of the stomal stricture in 61 patients. Dilation was done in 1 to 5 sessions and it was successful in all patients without a need for surgical revision. However, the procedure was complicated by perforation in $2.2 \%$ of all dilations (3 patients) [35]. In another series by Go et al which included 38 patients with stomal stenosis after RYGBP, the success rate of endoscopic balloon dilation was $95 \%$ with a $3 \%$ complication rate [36]. Similar results were published by Peifer et al in their cohort of 43 patients, in which 2 endoscopic dilation sessions up to $15 \mathrm{~mm}$ were successful in $93 \%$ of the patients without any perforations[34]. Laparoscopic gastric banding (LGB) can be complicated with band erosion and band slippage in $1 \%$ and $4.9 \%$ of procedures performed, respectively [37]. Band erosion can be seen by endoscopy as a white ring in retroflexion in the stomach. Removal of the gastric band can be successfully done with endoscopy, especially if more than $50 \%$ of the band eroded through the wall of the stomach. Expectant management is advisable when less than $50 \%$ of the gastric band eroded through the stomach wall [38]. Successful removal of gastric bands was described in many case reports by cutting the thinnest part of the band using papillotome, mixed current Argon Plasma Coagulation or with scissors [39-41].

Choleithiasis and its related billiary complications are common after bariatric surgery [42]. Occasionally, the endoscopists will face the challenge of accessing the bypassed intestinal limb to the ampulla of vater in order to perform billiary procedures [43]. Many techniques have been described in order to access the ampulla of vater in this circumstance. Wright et al described their experience in 15 patients with RYGBP who underwent billiary interventions. Initially, forward-viewing colonoscope was used to explore the afferent limb to find the ampulla. Billiary cannulation with the use of the colonoscope was achieved in 2 patients. In the rest of the patients, a guidewire was left and duodenoscope was advanced over the guidewire to the ampulla. This technique was successful in two-thirds of the enrolled patients [44]. Another described technique includes the use of the double balloon enteroscopy for ERCP.The feasibility of this technique was illustrated in many case series with a success rate of $80-90 \%$ in cannulating the common bile duct (CBD) and a more than $60 \%$ success rate in performing therapeutic intervention of the biliary tract [45-47]. The use of double balloon enteroscopy offers the advantage of exploration of the afferent limb in less 
time; , however, the lack of elevator could be problematic in gaining deep access of the CBD, especially in patients with naive papilla. Another novel technique utilizes the creation of a gastrostomy tube by an interventional radiologist in the excluded part of the stomach followed by the use of an ERCP endoscope through the gastrostomy[48]. Although this technique enables the use of an ERCP endoscope, it requires delaying the ERCP until maturation of the gastrostomy tube. A new technique of laparoscopic-assisted ERCP was proven to be successful in RYGBP patients [49]. Initially, a laparoscopic examination is done, followed by identification of the stomach remnant to create gastrostomy as an access for the ERCP endoscope. The endoscope is inserted through trochar from the abdominal wall to the gastrostomy opening and then to the biliary tract. This technique was successful in 9 out of 10 patients included in the study by Lopes et al. These impressive results were confirmed by Bertin et al, in which successful biliary cannulation was achieved in $94 \%$ of 21 RYGBP patients who underwent laparoscopic assisted ERCP [50]. In conclusion, bariatric surgeries are increasing due to the obesity epidemic. Endoscopists will have a major role in either evaluating these patients prior to surgery or in treating post-surgical complications.

\subsection{Endoscopy in treatment of post-surgical leaks and fistulas}

Anastomotic leaks are one of the major complications after gastrointestinal surgery. After laparoscopic RYGBP, anastomotic leaks can develop in 0.3 to $8 \%$ of patients[51]. Traditionally these leaks were managed surgically. The introduction of self-expandable removable stents offered a less invasive approach for management of anastomotic leak. In a retrospective study that included 5 patients with anastomotic leak and one patient with chronic gastrocutaneous fistula; self-expandable plastic stent was successful in closing the leak in all 5 patients but not in the patient with the fistula [52]. In another retrospective study that included 11 patients with acute leak and 2 patients with chronic fistula as a complication of bariatric surgery, self-expandable removal stents (metal and plastic) were successful in healing the acute leak in $89 \%$ of patients and one of the two patients with chronic fistula [53]. A new endoscopic device named "over the scope clip(OSC)," which utilizes a combination of clip with grasper and large suction cap to ensure serosa to serosa closure, was recently introduced to clinical practice. The new system has been evaluated in 12 patients with post-operative leaks or fistula with successful closure in 10 patients [54]. Currently, this system is approved in Europe but is not yet available for clinical use in United States. The recently published experiences of the use of this new OSC in different applications such as leaks, fistula and perforation are extremely encouraging [54-57].

\section{Endoscopy as an alternative to laparoscopy}

The recent advances in therapeutic endoscopy opened a new frontier for endoscopists to manage complicated clinical scenarios that were only managed surgically in the past. In this section we are going to discuss a few examples of the use of endoscopy in these clinical scenarios where surgery is contraindicated or considered a more invasive approach.

\subsection{Endoscopic gallbladder drainage}

Cholecystectomy (mainly by laparoscopic approach) is the standard of care for management of acute cholecystitis. In high risk patients for surgery percutaneous cholecystostomy is advocated as a temporarizing measure [58]. However, this approach could be problematic in patients with coagulopathy or due to anatomical reasons. In addition, an indwelling catheter 
is predisposed to infection and it reduces the quality of life. Endoscopic transpapillary drainage was introduced as a more attractive approach in this subset of patients. The technique utilizes the ERCP endoscope to cannulate the billiary tree and the cystic duct followed by placement of cystic duct stent or a nasocholecystic catheter in the gallbladder $[59,60]$. The outcome of this endoscopic approach was evaluated retrospectively in 35 surgically high-risk patients with acute cholecystitis. Nasocholecystic catheter was inserted in 21 patients, plastic stent in 6 patients and combined approach in 2 patients. The procedure was not successful in 6 of the 35 patients $(17 \%)$. Among the 29 patients with successful gallbladder drainage, 24 patients clinically improved within 3 days, while 4 patients died of septic complications. Although this technique was successful in $83 \%$ of the patients, longterm follow-up showed a $20 \%$ relapse rate for acute pancreatitis which emphasizes the role of this approach as a bridge until the patient is surgically fit [61].

\subsection{Endoscopic treatment of GERD}

Endoscopic treatment of GERD has been an attractive topic for the last 15 years. Hope for a successful cure of GERD with endoscopy has been a rollercoaster. In this section we will briefly discuss various endoscopic modalities currently available for GERD treatment. One of the earliest devices to treat GERD by endoscopic approach is the "Stretta Device". This device uses thermal coaogulation of the mucosa of the lower esophageal sphincter (LES) in order to narrow the esophagus and prevent GERD. Although the device showed modest success, its clinical use was hindered by the higher rate of complications such as esophageal perforation and aspiration pneumonia. Currently this system is not commercially available $[62,63]$. Other devices utilize suturing techniques to produce endoscopic plication of the LES in an effort to decrease GERD. There are more than five plicator devices available in the market. There are multiple cases series and non-randomized trials investigating the effectiveness of this technique. In summary, it showed a modest decrease in acid reflux but the procedure is lengthy and there is an increased risk of complication [64-66]. Based on the available data, it is premature to support incorporating these devices in clinical practice. A third technique that involves injecting bulking agents at the LES to prevent GERD has been recently introduced. The injected materials are either plexigal microsphere or ethylene vinyl alcohol (biodegradable microsphere) as in the Enteryx device. Although the technique is easy to use, the Enteryx device was recalled by the United States' Food and Drug Administration due to the associated complications such esophageal abscess, polymer migration and death [67-69]. Although many of the above mentioned results are disappointing, there are other devices currently being researched which could alter the current grim look for use of endoscopy in GERD.

\subsection{Endoscopic myotomy for esophageal achalasia}

Traditionally, the endoscopy role in achalasia was limited to endoscopic dilation and endoscopic injection of BOTOX [70]. A new technique involving creating a submucosal tunnel in the lower esophagus followed by advancing the endoscope in the new created space to the lower esophageal sphincter (LES) and electrocautery disruption of circular muscle of LES was proven feasible in an animal model [71]. This technique was proven successful in 17 patients with achalasia who underwent endoscopic myotomy in a tertiary referral center in Japan. Patients had significant improvement of their dysphagia and in the resting LES pressure. No major complications were reported [72]. The first case of 
endoscopic myotomy in the United States was reported in December 2010 by Stavropoulos et al; the procedure was successful with improvement in dysphagia in the follow-up period [73]. This technique has many advantages including the minimally invasive nature of the procedure, the lower incidence of reflux since only an incision of the circular muscle is done and the option of performing laparoscopic myotomy if needed. However, long-term data are not yet available for this new approach.

\section{References}

[1] Feingold, D.L., et al., Safety and reliability of tattooing colorectal neoplasms prior to laparoscopic resection. J Gastrointest Surg, 2004. 8(5): p. 543-6.

[2] Lane, K.L., et al., Endoscopic tattoo agents in the colon. Tissue responses and clinical implications. Am J Surg Pathol, 1996. 20(10): p. 1266-70.

[3] Price, N., et al., Safety and efficacy of India ink and indocyanine green as colonic tattooing agents. Gastrointest Endosc, 2000. 51(4 Pt 1): p. 438-42.

[4] Yeung, J.M., C. Maxwell-Armstrong, and A.G. Acheson, Colonic tattooing in laparoscopic surgery - making the mark? Colorectal Dis, 2009. 11(5): p. 527-30.

[5] Nizam, R., et al., Colonic tattooing with India ink: benefits, risks, and alternatives. Am J Gastroenterol, 1996. 91(9): p. 1804-8.

[6] Askin, M.P., et al., Tattoo of colonic neoplasms in 113 patients with a new sterile carbon compound. Gastrointest Endosc, 2002. 56(3): p. 339-42.

[7] Shatz, B.A., et al., Long-term safety of India ink tattoos in the colon. Gastrointest Endosc, 1997. 45(2): p. 153-6.

[8] Singh, S., et al., Complication after pre-operative India ink tattooing in a colonic lesion. Dig Surg, 2006. 23(5-6): p. 303.

[9] Lennon, A.M., et al., EUS-guided tattooing before laparoscopic distal pancreatic resection (with video). Gastrointest Endosc, 2010. 72(5): p. 1089-94.

[10] Newman, N.A., et al., Preoperative endoscopic tattooing of pancreatic body and tail lesions decreases operative time for laparoscopic distal pancreatectomy. Surgery, 2010. 148(2): p. 371-7.

[11] Vezakis, A., et al., Intraoperative cholangiography during laparoscopic cholecystectomy. Surg Endosc, 2000. 14(12): p. 1118-22.

[12] Clayton, E.S., et al., Meta-analysis of endoscopy and surgery versus surgery alone for common bile duct stones with the gallbladder in situ. Br J Surg, 2006. 93(10): p. 1185-91.

[13] Kharbutli, B. and V. Velanovich, Management of preoperatively suspected choledocholithiasis: a decision analysis. J Gastrointest Surg, 2008. 12(11): p. 1973-80.

[14] Enochsson, L., et al., Intraoperative endoscopic retrograde cholangiopancreatography (ERCP) to remove common bile duct stones during routine laparoscopic cholecystectomy does not prolong hospitalization: a 2-year experience. Surg Endosc, 2004. 18(3): p. 367-71.

[15] ElGeidie, A.A., G.K. ElEbidy, and Y.M. Naeem, Preoperative versus intraoperative endoscopic sphincterotomy for management of common bile duct stones. Surg Endosc, 2011. 25(4): p. 1230-7.

[16] Grunhagen, D.J., et al., Laparoscopic-monitored colonoscopic polypectomy: a multimodality method to avoid segmental colon resection. Colorectal Dis, 2010.

[17] Franklin, M.E., Jr., et al., Laparoscopic-assisted colonoscopic polypectomy: the Texas Endosurgery Institute experience. Dis Colon Rectum, 2000. 43(9): p. 1246-9. 
[18] Ommer, A., et al., [Laparoscopic-assisted colonoscopic polypectomy--indications and results]. Zentralbl Chir, 2003. 128(3): p. 195-8.

[19] Ludwig, K., et al., Laparoscopic-endoscopic rendezvous resection of gastric tumors. Surg Endosc, 2002. 16(11): p. 1561-5.

[20] Hiki, N., et al., Laparoscopic and endoscopic cooperative surgery for gastrointestinal stromal tumor dissection. Surg Endosc, 2008. 22(7): p. 1729-35.

[21] Coimbra, C., et al., Laparoscopic repair of colonoscopic perforation: a new standard? Surg Endosc, 2010.

[22] Senadhi, V., et al., Combined colonoscopy and laparoscopy to close a colonic perforation. Endoscopy, 2010. 42 Suppl 2: p. E213-4.

[23] Alexander, S., et al., EMR of large, sessile, sporadic nonampullary duodenal adenomas: technical aspects and long-term outcome (with videos). Gastrointest Endosc, 2009. 69(1): p. 66-73.

[24] Abbass, R., J. Rigaux, and F.H. Al-Kawas, Nonampullary duodenal polyps: characteristics and endoscopic management. Gastrointest Endosc, 2010. 71(4): p. 754-9.

[25] Sakon, M., et al., A novel combined laparoscopic-endoscopic cooperative approach for duodenal lesions. J Laparoendosc Adv Surg Tech A, 2010. 20(6): p. 555-8.

[26] Lanitis, S., et al., Combined laparoscopic and endoscopic approach for the management of two ingested sewing needles: one migrated into the liver and one stuck in the duodenum. J Laparoendosc Adv Surg Tech A, 2007. 17(3): p. 311-4.

[27] Olson, J.A., Jr., L.B. Weinstock, and L.M. Brunt, Combined endoscopic and laparoscopic approach to remove a sharp gastric foreign body. Gastrointest Endosc, 2000. 51(4 Pt 1): p. 500-2.

[28] Iafrati, M.D., et al., A novel approach to the removal of sharp foreign bodies from the stomach using a combined endoscopic and laparoscopic technique. Gastrointest Endosc, 1996. 43(1): p. 67-70.

[29] Padwal, R., S.K. Li, and D.C. Lau, Long-term pharmacotherapy for obesity and overweight. Cochrane Database Syst Rev, 2004(3): p. CD004094.

[30] Buchwald, H. and S.E. Williams, Bariatric surgery worldwide 2003. Obes Surg, 2004. 14(9): p. 1157-64.

[31] Podnos, Y.D., et al., Complications after laparoscopic gastric bypass: a review of 3464 cases. Arch Surg, 2003. 138(9): p. 957-61.

[32] Msika, S., [Surgery for morbid obesity: 2. Complications. Results of a Technologic Evaluation by the ANAES]. J Chir (Paris), 2003. 140(1): p. 4-21.

[33] Kothari, S.N., et al., Excellent laparoscopic gastric bypass outcomes can be achieved at a community-based training hospital with moderate case volume. Ann Surg, 2010. 252(1): p. 43-9.

[34] Peifer, K.J., et al., Successful endoscopic management of gastrojejunal anastomotic strictures after Roux-en-Y gastric bypass. Gastrointest Endosc, 2007. 66(2): p. 248-52.

[35] Ukleja, A., et al., Outcome of endoscopic balloon dilation of strictures after laparoscopic gastric bypass. Surg Endosc, 2008. 22(8): p. 1746-50.

[36] Go, M.R., et al., Endoscopic management of stomal stenosis after Roux-en-Y gastric bypass. Surg Endosc, 2004. 18(1): p. 56-9.

[37] Singhal, R., et al., Band slippage and erosion after laparoscopic gastric banding: a metaanalysis. Surg Endosc, 2010. 24(12): p. 2980-6.

[38] Neto, M.P., et al., Endoscopic removal of eroded adjustable gastric band: lessons learned after 5 years and 78 cases. Surg Obes Relat Dis, 2010. 6(4): p. 423-7. 
[39] Meyenberger, C., C. Gubler, and P.M. Hengstler, Endoscopic management of a penetrated gastric band. Gastrointest Endosc, 2004. 60(3): p. 480-1.

[40] De Palma, G.D., et al., Endoscopic management of intragastric penetrated adjustable gastric band for morbid obesity. World J Gastroenterol, 2006. 12(25): p. 4098-100.

[41] Weiss, H., et al., Gastroscopic band removal after intragastric migration of adjustable gastric band: a new minimal invasive technique. Obes Surg, 2000. 10(2): p. 167-70.

[42] Caruana, J.A., et al., Incidence of symptomatic gallstones after gastric bypass: is prophylactic treatment really necessary? Surg Obes Relat Dis, 2005. 1(6): p. 564-7; discussion 567-8.

[43] Lopes, T.L. and T.H. Baron, Endoscopic retrograde cholangiopancreatography in patients with Roux-en-Y anatomy. J Hepatobiliary Pancreat Sci, 2010.

[44] Wright, B.E., O.W. Cass, and M.L. Freeman, ERCP in patients with long-limb Roux-en-Y gastrojejunostomy and intact papilla. Gastrointest Endosc, 2002. 56(2): p. 225-32.

[45] Monkemuller, K., et al., ERCP with the double balloon enteroscope in patients with Roux-en$Y$ anastomosis. Surg Endosc, 2009. 23(9): p. 1961-7.

[46] Parlak, E., et al., Endoscopic retrograde cholangiography by double balloon enteroscopy in patients with Roux-en-Y hepaticojejunostomy. Surg Endosc, 2010. 24(2): p. 466-70.

[47] Moreels, T.G., et al., Diagnostic and therapeutic double-balloon enteroscopy after small bowel Roux-en-Y reconstructive surgery. Digestion, 2009. 80(3): p. 141-7.

[48] Martinez, J., et al., Endoscopic retrograde cholangiopancreatography and gastroduodenoscopy after Roux-en-Y gastric bypass. Surg Endosc, 2006. 20(10): p. 1548-50.

[49] Lopes, T.L., R.H. Clements, and C.M. Wilcox, Laparoscopy-assisted ERCP: experience of a high-volume bariatric surgery center (with video). Gastrointest Endosc, 2009. 70(6): p. 1254-9.

[50] Bertin, P.M., K. Singh, and M.E. Arregui, Laparoscopic transgastric endoscopic retrograde cholangiopancreatography (ERCP) after gastric bypass: case series and a description of technique. Surg Endosc, 2011.

[51] Baker, R.S., et al., The science of stapling and leaks. Obes Surg, 2004. 14(10): p. 1290-8.

[52] Edwards, C.A., et al., Management of anastomotic leaks after Roux-en-Y bypass using selfexpanding polyester stents. Surg Obes Relat Dis, 2008. 4(5): p. 594-9; discussion 599600.

[53] Eubanks, S., et al., Use of endoscopic stents to treat anastomotic complications after bariatric surgery. J Am Coll Surg, 2008. 206(5): p. 935-8; discussion 938-9.

[54] Manta, R., et al., Endoscopic treatment of gastrointestinal fistulas using an over-the-scope clip (OTSC) device: Case series from a tertiary referral center. Endoscopy, 2011.

[55] Iacopini, F., et al., Over-the-scope clip closure of two chronic fistulas after gastric band penetration. World J Gastroenterol, 2010. 16(13): p. 1665-9.

[56] von Renteln, D., M.C. Vassiliou, and R.I. Rothstein, Randomized controlled trial comparing endoscopic clips and over-the-scope clips for closure of natural orifice transluminal endoscopic surgery gastrotomies. Endoscopy, 2009. 41(12): p. 1056-61.

[57] Repici, A., et al., Clinical experience with a new endoscopic over-the-scope clip system for use in the GI tract. Dig Liver Dis, 2009. 41(6): p. 406-10.

[58] Ito, K., et al., Percutaneous cholecystostomy versus gallbladder aspiration for acute cholecystitis: a prospective randomized controlled trial. AJR Am J Roentgenol, 2004. 183(1): p. 193-6.

[59] Itoi, T., et al., Endoscopic transpapillary gallbladder drainage in patients with acute cholecystitis in whom percutaneous transhepatic approach is contraindicated or anatomically impossible (with video). Gastrointest Endosc, 2008. 68(3): p. 455-60. 
[60] Comin, J.M., R.J. Cade, and A.F. Little, Percutaneous cystic duct stent placement in the treatment of acute cholecystitis. J Med Imaging Radiat Oncol, 2010. 54(5): p. 457-61.

[61] Mutignani, M., et al., Endoscopic gallbladder drainage for acute cholecystitis: technical and clinical results. Endoscopy, 2009. 41(6): p. 539-46.

[62] Chen, D., et al., Systematic review of endoscopic treatments for gastro-oesophageal reflux disease. Br J Surg, 2009. 96(2): p. 128-36.

[63] Romagnuolo, J., Endoscopic "antireflux" procedures: not yet ready for prime time. Can J Gastroenterol, 2004. 18(9): p. 573-7.

[64] Thomson, M., et al., Endoluminal gastroplication in children with significant gastrooesophageal reflux disease. Gut, 2004. 53(12): p. 1745-50.

[65] Chuttani, R., et al., A novel endoscopic full-thickness plicator for the treatment of GERD: A pilot study. Gastrointest Endosc, 2003. 58(5): p. 770-6.

[66] Schiefke, I., et al., Use of an endoscopic suturing device (the "ESD") to treat patients with gastroesophageal reflux disease, after unsuccessful EndoCinch endoluminal gastroplication: another failure. Endoscopy, 2005. 37(8): p. 700-5.

[67] Wong, R.F., T.V. Davis, and K.A. Peterson, Complications involving the mediastinum after injection of Enteryx for GERD. Gastrointest Endosc, 2005. 61(6): p. 753-6.

[68] Veerappan, G.R., J.M. Koff, and M.T. Smith, Enteryx polymer migration to lymph nodes and beyond. Endoscopy, 2008. 40 Suppl 2: p. E10-1.

[69] Noh, K.W., et al., Pneumomediastinum following Enteryx injection for the treatment of gastroesophageal reflux disease. Am J Gastroenterol, 2005. 100(3): p. 723-6.

[70] Urbach, D.R., et al., A decision analysis of the optimal initial approach to achalasia: laparoscopic Heller myotomy with partial fundoplication, thoracoscopic Heller myotomy, pneumatic dilatation, or botulinum toxin injection. J Gastrointest Surg, 2001. 5(2): p. 192-205.

[71] Pasricha, P.J., et al., Submucosal endoscopic esophageal myotomy: a novel experimental approach for the treatment of achalasia. Endoscopy, 2007. 39(9): p. 761-4.

[72] Inoue, H., et al., Peroral endoscopic myotomy (POEM) for esophageal achalasia. Endoscopy, 2010. 42(4): p. 265-71.

[73] Stavropoulos, S.N., et al., Endoscopic submucosal myotomy for the treatment of achalasia (with video). Gastrointest Endosc, 2010. 72(6): p. 1309-11. 


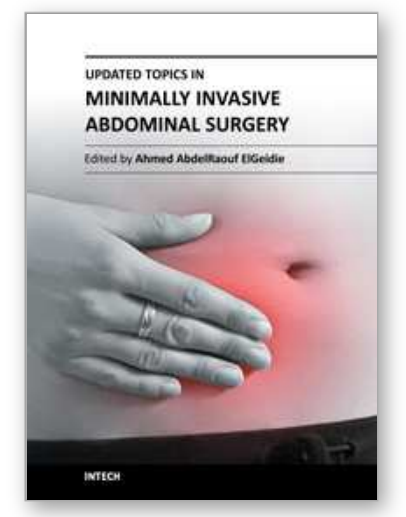

\author{
Updated Topics in Minimally Invasive Abdominal Surgery \\ Edited by Prof. Ahmed Elgeidie
}

ISBN 978-953-307-773-4

Hard cover, 246 pages

Publisher InTech

Published online 14, November, 2011

Published in print edition November, 2011

Updated topics in minimally invasive abdominal surgery provides surgeons interested in minimally invasive abdominal surgery with the most recent techniques and discussions in laparoscopic surgery. This book includes different topics covering a big variety of medical conditions with up-to-date information. It discusses many controversies in a clear and user-friendly manner. This book is made for young junior surgeons in training and also senior surgeons who need to know the most recent work in the field of laparoscopy. To make the material easily digestive, we provided the book with many figures and illustrations for different procedures and technical pearls.

\title{
How to reference
}

In order to correctly reference this scholarly work, feel free to copy and paste the following:

Mohamed O. Othman, Mihir Patel and Timothy Woodward (2011). Role of Endoscopy in Laparoscopic Procedures, Updated Topics in Minimally Invasive Abdominal Surgery, Prof. Ahmed Elgeidie (Ed.), ISBN: 978953-307-773-4, InTech, Available from: http://www.intechopen.com/books/updated-topics-in-minimallyinvasive-abdominal-surgery/role-of-endoscopy-in-laparoscopic-procedures

\section{INTECH}

open science | open minds

\section{InTech Europe}

University Campus STeP Ri Slavka Krautzeka 83/A 51000 Rijeka, Croatia Phone: +385 (51) 770447

Fax: +385 (51) 686166 www.intechopen.com

\section{InTech China}

Unit 405, Office Block, Hotel Equatorial Shanghai No.65, Yan An Road (West), Shanghai, 200040, China 中国上海市延安西路65号上海国际贵都大饭店办公楼405单元 Phone: +86-21-62489820

Fax: $+86-21-62489821$ 
(C) 2011 The Author(s). Licensee IntechOpen. This is an open access article distributed under the terms of the Creative Commons Attribution 3.0 License, which permits unrestricted use, distribution, and reproduction in any medium, provided the original work is properly cited. 